\title{
Correction to: Fixing the Leaky Pipeline for Talented Women in STEM
}

\author{
Ainur Almukhambetova ${ }^{1}$ (D) Daniel Hernández-Torrano ${ }^{1} \cdot$ Alexandra Nam $^{1}$
}

(c) Ministry of Science and Technology, Taiwan 2022

\section{Correction to: International Journal of Science and Mathematics Education https://doi.org/10.1007/s10763-021-10239-1}

The original version of this article unfortunately contained missing grant number in Funding information.

Funding Nazarbayev University (021220FD3051).

The original article has been corrected.

The original article can be found online at https://doi.org/10.1007/s10763-021-10239-1.

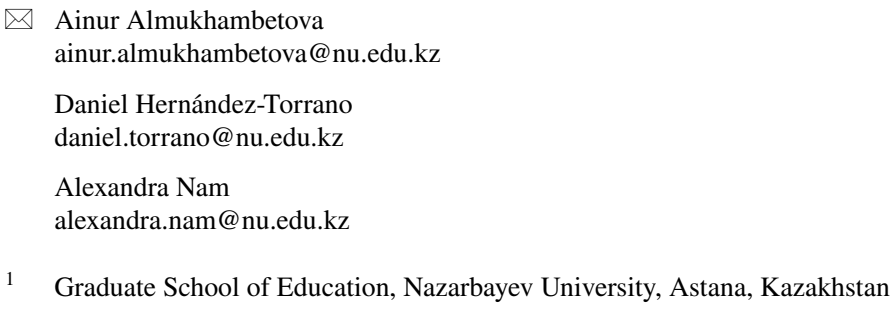

